Check for updates

Cite this: RSC Adv., 2019, 9, 33890

Received 3rd September 2019

Accepted 14th October 2019

DOI: 10.1039/c9ra07031a

rsc.li/rsc-advances

\title{
Temperature-induced structural diversity of metal-organic frameworks and their applications in selective sensing of nitrobenzene and electrocatalyzing the oxygen evolution reaction $\uparrow$
}

\author{
Defang Han, ${ }^{a}$ Kun Huang, (D) ${ }^{* a}$ Xianglin Li, ${ }^{a}$ Mengni Peng, ${ }^{a}$ Linhai Jing, ${ }^{a}$ Baoyi $Y u,{ }^{b}$ \\ Zeqin Chen ${ }^{\star a c}$ and Dabin Qin*a
}

\begin{abstract}
Structural diversities are presented in four new Co-MOFs containing 1,5-bi(imidazolyl)anthracene and different dibenzobarrelene skeletons based on dicarboxylic acid, in which MOFs 1-3 exhibit 2D networks in a 4-connected node sql topology with the point symbol of $\left\{4^{4} \cdot 6^{2}\right\}$, while MOF 4 forms a $1 \mathrm{D}$ chain structure. It is clearly observed that the 2D-1D structural transformation of 2-4 has been realized by temperature modulated hydrothermal synthesis procedures from $120-160{ }^{\circ} \mathrm{C}$, suggesting the key role of temperature for constructing MOFs. In addition, obvious $\pi-\pi$ interactions between anthracene rings can be observed in the architectures of 1-3, which may favorably stabilize their 2D supramolecular networks. More importantly, fluorescence behaviors of 1-4 have been investigated in water among various nitroaromatic compounds (NACs) and the results show that all samples exhibit high selectivity and fine sensitivity to nitrobenzene (NB) with fluorescence quenching, which is confirmed to be the result of electron transfer from the excited state of ligands to that of NB by density functional theory. Furthermore, MOFs 1-4 have been directly employed as electrocatalysts for the oxygen evolution reaction (OER), in which MOF 4 gives the best activity towards the OER among all as-synthesized samples with an overpotential of $398 \mathrm{mV}$ at a current density of $10 \mathrm{~mA} \mathrm{~cm}{ }^{-2}$ and a low Tafel slope of $59 \mathrm{mV} \mathrm{dec}{ }^{-1}$.
\end{abstract}

\section{Introduction}

In the past decades, much attention has been paid to the exploitation of metal-organic frameworks (MOFs), a new class of porous coordination materials, owing to their advantages of tailorable porosity and tunable structures, fantastic topologies, and high surface area, ${ }^{1}$ which exhibit excellent performance in fuel gas storage, heterogeneous catalysis, drug delivery system, targeted cancer therapy, luminescent materials and so on. ${ }^{2}$ Generally, the application of MOFs largely depends on their

${ }^{a}$ Key Laboratory of Chemical Synthesis and Pollution Control of Sichuan Province, School of Chemistry and Chemical Engineering, China West Normal University, Nanchong 637002, P. R. China.E-mail: hkun2017@cwnu.edu.cn; qdbkyl@cwnu. edu.cn

${ }^{b}$ Key Laboratory of Urban Agriculture (North China), Ministry of Agriculture, College of Biological Sciences Engineering, Beijing University of Agriculture, Beijing 102206, P. R. China

${ }^{c}$ College of Materials and Chemistry and Chemical Engineering, Chengdu University of Technology, Chengdu, 610059, P. R. China. E-mail: chenzeqin@sina.com

$\dagger$ Electronic supplementary information (ESI) available: Crystal data, additional figures, TGA, PXRD, IR spectra, optical spectra or other electronic format. CCDC 1887850, 1887851, 1887854 and 1887855 for compounds 1-4. For ESI and crystallographic data in CIF or other electronic format see DOI: 10.1039/c9ra07031a architectural features. As a result, it is a great challenge and of significance to adopt a new synthetic method in preparing MOFs with targeted architectures and expected properties. In an earlier report, multidentate ligands, including multi-imidazole and multi-carboxylate, have been used as building blocks for constructing MOFs with fascinating structures, novel topologies and varieties of applications. ${ }^{2 c, 3}$ In addition, to make full utilization of the coordination sites in imidazole/carboxylate, mixed ligands of them have been employed for the construction of various functional MOFs, which achieves remarkable progress in tailoring structures and improving properties. ${ }^{4}$ However, the structural formation of MOF may suffer from several factors, such as temperature, metal centers, organic linkers, solvent, and so on. ${ }^{5}$ Among them, temperature plays key role for the formation of structural mold, and different temperature can lead to the diversity of MOFs from the same starting materials. Besides, the utilization of several aromatic rings contained rigid ligands in construction of MOFs may contribute to stable frameworks via $\pi$-stacking interactions among aromatic rings, ${ }^{6}$ which are also considered easily to predict the final topologies compared to that of the flexible ligands ${ }^{1 b, 7}$ Meanwhile, introduction of aromatic $\pi$-rings in organic ligands may enhance the host-guest chemical interactions between the analytes and 
MOFs in chemical sensing. ${ }^{3 e, 8}$ As far as we know, there are some examples for constructing MOFs with the same metal core involving rigid hybrid ligands of multi-imidazole and multicarboxylate, however, the researches on the relationship between the architectures and temperature are rather rare. ${ }^{5 a-g}$

Up to date, a great variety of MOFs have been applied in chemical sensing via the interactions between the target analyst and the porosity/surface area of MOFs. ${ }^{9}$ Particularly, chemical sensing based on the fluorescence changes is considered as a simple, sensitive and rapid method for recognizing ions, molecules and so on. Recently, developing MOF-based chemical sensors for detection of NACs attracts extensive attention owing to the high explosiveness and hazardousness of NACs, which are of great significance for public security and environmental protection. ${ }^{10}$ As a member of NACs, NB is widely used as solvent and intermedia in chemical synthesis, which gradually causes concerns for its environmental pollution. Though several examples of MOFs-based sensors have been reported with sensing ability towards NB, ${ }^{11}$ to our knowledge, most of them suffered from interferences caused by other NACs and thus showed low selectivity to NB among variety of NACs (Table S1†). ${ }^{11 a-h}$ Consequently, it is highly desirable to explore efficient MOF-based sensors that can detect NB with high selectivity and sensitivity by fluorescent response. On the other hand, developing efficient electrocatalysts for oxygen evolution reaction (OER) presents as an attractive strategy in clean energy generation and storage. ${ }^{12}$ Actually, OER is generally considered to baffle the electrocatalytic water splitting due to its kinetically sluggish, low efficiency, poorly structural stability and etc. ${ }^{13}$ As such, to utilize proper and highly efficient catalysts in electricity-driven systems for water splitting to produce oxygen is significant and challenging. For the reasons mentioned above, MOFs have emerged as a class of promising electrocatalytic catalysts owing to their advantages in porous structure, active surface area, and open metal sites, which may facilitate the enhancement of catalytic activity. So far, enormous MOFbased catalysts have been designed and developed with excellent OER activities, some of which could comparably with nonprecious metal electrocatalysts, displaying great potentials for developing electrocatalytic OER materials. ${ }^{14}$ Nevertheless, developing MOF based electrocatalysts for OER is still in its infant stage, especially, a limited number of pristine MOFs have been reported for direct use in catalytic OER. Therefore, exploring low-cost but efficient pristine MOF electrocatalysts for OER is significant and challenging.

In consideration of the aforementioned as well as our continuous research for development and application of MOFs, herein, mixed organic ligands including rigid 1,5-bi(imidazolyl)anthracene and dibenzobarrelene skeletons based dicarboxylic acid were introduced to construct a series of luminescent 2D/1D Co-MOFs (14) for the first time (Scheme 1). Meanwhile, a facile method via varying temperature to tailor the structures of MOFs has been conducted successfully during the hydro-thermal processes. Then the luminescent behaviors of all prepared MOFs were systematically investigated, which showed obvious solvent-dependent fluorescent spectra and exhibited high selectivity and fine sensitivity towards NB among various NACs by fluorescence quenching. Moreover, the

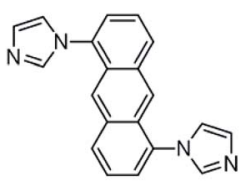

L1

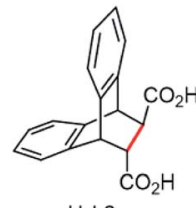

$\mathrm{H}_{2} \mathrm{~L} 2$

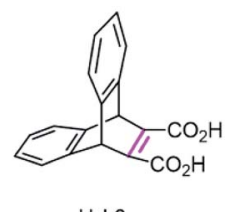

$\mathrm{H}_{2} \mathrm{~L} 3$
Scheme 1 The structures of bidentate imidazole ligand L1 and dibenzobarrelene based carboxylic acid ligands $\mathrm{H}_{2} \mathrm{~L} 2$ and $\mathrm{H}_{2} \mathrm{~L} 3$.

specific response to NB was further demonstrated by density functional theory (DFT) calculations. Significantly, MOFs 1-4 have been directly employed as electrocatalysts for oxygen evolution reaction (OER), in which MOF 4 showed the best activity towards OER among all as-synthesized samples, achieving overpotential of $398 \mathrm{mV}$ at current density of $10 \mathrm{~mA} \mathrm{~cm}{ }^{-2}$ and Tafel slope of $59 \mathrm{mV}$ $\mathrm{dec}^{-1}$. We anticipate this work can shed light on fabricating MOFs with structural diversity via temperature regulation and applying MOFs in sensing and electrocatalytic OER materials.

\section{Experimental}

\section{Materials and methods}

All chemicals were obtained from Aladdin (Shanghai) or Chengdu Kelong Chemical Co., Ltd. (Chengdu). $\mathbf{H}_{2} \mathbf{L} 2$ and $\mathbf{H}_{2} \mathbf{L} 3$ were synthesized according to the previous method..$^{15}$ NMR spectra were recorded on a Bruker advance II $400 \mathrm{MHz}$ NMR spectrometer. All FT-IR absorption spectroscopy were obtained from a Nicolet 6700 with $\mathrm{KBr}$ pellets. X-ray powder diffractions were collected by Rigaku Dmax/Ultima IV diffractometer. Thermogravimetric analyses (TGA) were obtained from a Netzsch STA 449 F3 thermal analyzer. Elemental analyses were acquired from a PerkinElmer 240 elemental analyzer. Nitrogen adsorption isotherms were recorded at $77 \mathrm{~K}$ via Autosorb-IQ gas analyzer. Brunauer-Emmett-Teller (BET) method was employed for evaluating the specific surface area and pore size distribution. Fluorescence measurements were conducted on a Cary Eclipse fluorescence spectrophotometer. Electrochemical activities of 1-4 for OER were examined using a CHI$660 \mathrm{E}$ electrochemical workstation equipped with a standard three electrode system.

Synthesis of 1,5-bi(imidazolyl)anthracene (L1). To a dry DMF $(20 \mathrm{~mL})$ solution of imidazole $(5.0 \mathrm{~g}, 73.5 \mathrm{mmol})$ in a $100 \mathrm{~mL}$ two-necked flask were wadded $\mathrm{NaH}(3.0 \mathrm{~g}, 125.0 \mathrm{mmol})$, which were stirred at room temperature for $0.5 \mathrm{~h}$, followed by addition of 1,5-dichloroanthracene ( $1 \mathrm{~g}, 4.1 \mathrm{mmol})$ and $\mathrm{CuI}(0.57 \mathrm{~g}, 3.0$ $\mathrm{mmol}$ ) under $\mathrm{N}_{2}$ atmosphere. The resulting mixture was heated to $140{ }^{\circ} \mathrm{C}$ for 48 hours and cooled to room temperature. After that, the reaction mixture was poured into $100 \mathrm{~mL}$ water and extracted with $\mathrm{CH}_{2} \mathrm{Cl}_{2}(50 \mathrm{~mL} \times 3)$. The combined organic layers were dried over anhydrous $\mathrm{Na}_{2} \mathrm{SO}_{4}$ and evaporated to remove the solvent. The residue was purified by column chromatography to obtain the target product in $40 \%$ yield $(0.5 \mathrm{~g})$. Mp: $260-262{ }^{\circ} \mathrm{C}^{1} \mathrm{H}$ NMR (400 MHz, DMSO-d 6 ) $\delta 8.35(\mathrm{~s}, 2 \mathrm{H})$, 8.26-8.22 (m, 2H), $8.10(\mathrm{~s}, 2 \mathrm{H}), 7.69(\mathrm{~s}, 1 \mathrm{H}), 7.66-7.63(\mathrm{~m}, 4 \mathrm{H})$, $7.29(\mathrm{~s}, 2 \mathrm{H}) .{ }^{13} \mathrm{C}$ NMR (100 MHz, DMSO-d $\left.{ }_{6}\right) \delta 138.59,133.65$, 
132.16, 129.70, 129.20, 127.55, 125.59, 124.07, 122.14, 121.99. Anal. calcd (\%) for $\mathrm{C}_{20} \mathrm{H}_{14} \mathrm{~N}_{4}$ : C, 90.29; $\mathrm{H}, 4.51 ; \mathrm{N}, 20.6$; found: $\mathrm{C}$, 90.40; H, 4.50; N, 20.56. HRMS calcd $m / z 311.1297$ for $[\mathrm{M}+\mathrm{H}]^{+}$, found $m / z 311.1309$ for $[\mathrm{M}+\mathrm{H}]^{+}$.

Synthesis of $\left\{\left[\mathrm{Co}_{2}(\mathrm{L1})_{2}(\mathrm{~L} 2)_{2} \cdot\left(\mathrm{H}_{2} \mathrm{O}\right)_{2}\right]_{n} \cdot 3 \mathrm{H}_{2} \mathrm{O}\right\}$ (1). A mixture of L1 (15.5 mg, $0.05 \mathrm{mmol}), \mathbf{H}_{2} \mathbf{L} 2(14.7 \mathrm{mg}, 0.05 \mathrm{mmol})$ and $\mathrm{Co}(\mathrm{NO})_{3} \cdot 6 \mathrm{H}_{2} \mathrm{O}(29.1 \mathrm{mg}, 0.1 \mathrm{mmol})$ were dissolved in a mixture solution of $\mathrm{CH}_{3} \mathrm{CN}(2 \mathrm{~mL})$ and $\mathrm{H}_{2} \mathrm{O}(6 \mathrm{~mL})$, which was heated to $120{ }^{\circ} \mathrm{C}$ with a heating rate of $3{ }^{\circ} \mathrm{C} \mathrm{min}{ }^{-1}$ and reacted for $96 \mathrm{~h}$ in a $20 \mathrm{~mL}$ Teflon vial. Then the reaction was cooled down to room temperature to obtain purplish red block crystals in $72 \%$ yield (based on $\mathbf{L 1}$ ligand). Elemental analysis (\%), calcd for $\mathrm{C}_{76} \mathrm{H}_{62} \mathrm{Co}_{2} \mathrm{~N}_{8} \mathrm{O}_{13}$ : C, 64.53; $\mathrm{H}, 4.38 ; \mathrm{N}, 7.92$; found: $\mathrm{C}, 63.72 ; \mathrm{H}$, 4.46; N, 7.83.

Synthesis of $\left\{\left[\mathrm{Co}_{2}(\mathrm{L1})_{2}(\mathrm{L3})_{2} \cdot\left(\mathrm{H}_{2} \mathrm{O}\right)_{2}\right]_{n} \cdot 4 \mathrm{H}_{2} \mathrm{O}\right\} \quad$ (2). To a mixture of $\mathbf{L 1}(15.5 \mathrm{mg}, 0.05 \mathrm{mmol})$ and $\mathbf{H}_{2} \mathbf{L} 3(29.2 \mathrm{mg}, 0.1$ $\mathrm{mmol}$ ) in $\mathrm{CH}_{3} \mathrm{CN} / \mathrm{H}_{2} \mathrm{O}$ solution $(8 \mathrm{~mL}, \mathrm{v} / \mathrm{v}=1 / 3)$ were added $\mathrm{Co}(\mathrm{NO})_{3} \cdot 6 \mathrm{H}_{2} \mathrm{O}(29.1 \mathrm{mg}, 0.1 \mathrm{mmol})$, which were heated to $120{ }^{\circ} \mathrm{C}$ at a heating rate of $3{ }^{\circ} \mathrm{C} \mathrm{min}{ }^{-1}$ in a Teflon vial and reacted for 96 hours. After cooled to room temperature, brownish blocks crystals of 2 were obtained in $48 \%$ yield (based on $\mathbf{L 1}$ ligand). Elemental analysis (\%), calcd for $\mathrm{C}_{76} \mathrm{H}_{60} \mathrm{Co}_{2} \mathrm{~N}_{8} \mathrm{O}_{14}$ : C, 63.90; H, 4.20; N, 7.85; found: C, 63.87; $\mathrm{H}$, 4.23 ; N, 7.84 .

Synthesis of $\left\{\left[\mathrm{Co}(\mathrm{L1})_{2}(\mathrm{HL} 3)_{2}\right]_{n} \cdot \mathbf{2 C H}_{3} \mathbf{C N}\right\}$ (3). The prepared procedure was according to that of 2 except for altering the heating temperature to $140{ }^{\circ} \mathrm{C}$. Brown block crystals of complex 3 were collected in $56 \%$ yield (based on L1 ligand). Elemental analysis (\%), calcd for $\mathrm{C}_{80} \mathrm{H}_{56} \mathrm{CoN}_{10} \mathrm{O}_{8}: \mathrm{C}, 71.41 ; \mathrm{H}, 4.17 ; \mathrm{N}$, 10.42; found: C, 71.47; $\mathrm{H}, 4.18$; N, 10.38.

Synthesis of $\left\{\left[\mathrm{Co}(\mathrm{L1})(\mathrm{HL} 3)_{2} \cdot\left(\mathrm{H}_{2} \mathrm{O}\right)_{2}\right]_{n}\right\}$ (4). The synthetic method was according to that of 2 only by altering the heating temperature to $160{ }^{\circ} \mathrm{C}$. Brown block crystals of 4 were obtained in $26 \%$ yield (based on $\mathbf{L 1}$ ligand). Elemental analysis (\%), calcd for $\mathrm{C}_{56} \mathrm{H}_{40} \mathrm{CoN}_{4} \mathrm{O}_{10}: \mathrm{C}, 68.09 ; \mathrm{H}, 4.08 ; \mathrm{N}, 5.67$; found: $68.06 ; \mathrm{H}$, 4.09; N, 5.65.

Crystallographic data collection and refinement. The crystal data for 1-4 were collected on a Bruker SMART APEX-II CCD diffractometer with graphite monochromatic Mo-K $\alpha$ radiation $(\lambda=0.71073 \AA)$ by using the $\omega$-scan technique at $293{ }^{\circ} \mathrm{C}$. All structures were solved by direct methods and refined with the full-matrix least-squares procedures on $F^{2}$ using the SHELXL-97 (ref. 16) and Olex-2 programs, respectively. All $\mathrm{H}$ atoms were generated geometrically at idealized positions at idealized positions and refined using the riding model. The CCDC deposition numbers allocated to $\mathbf{1 - 4}$ were 1887850, 1887851, 1887854 and 1887855 , respectively. Topology analyses were carried out by using TOPOS program. ${ }^{17}$ Corresponding data for 1-4 were provided in Tables $1, \mathrm{~S} 2$ and Fig. $\mathrm{S} 1 . \dagger$

\section{Results and discussion}

L1 was synthesized by a modified C-N coupling under the catalyst of $\mathrm{CuI}$ in about $40 \%$ yield as depicted in Scheme S1. $\dagger^{3 a}$ $\mathbf{H}_{2} \mathrm{~L} 2$ and $\mathbf{H}_{2} \mathrm{~L} 3$ were facilely prepared in a high yield via DielsAlder reaction and ester hydrolysis process according to literature. ${ }^{12}$ L1 was characterized by NMR spectra and HRMS (Fig. S1-S3 $\dagger$ ). MOFs 1-4 were characterized by FT-IR spectra (Fig. $\mathrm{S} 4 \dagger$ ).

\section{$\left\{\left[\mathrm{Co}_{2}(\mathrm{L1})_{2}(\mathrm{~L} 2)_{2} \cdot\left(\mathrm{H}_{2} \mathrm{O}\right)_{2}\right]_{n} \cdot 3 \mathrm{H}_{2} \mathrm{O}\right\}(1)$}

The single crystal X-ray data reveals complex 1 conforms to the triclinic crystal system, space group $P \overline{1}$. Fig. 1a shows an asymmetric unit of 1 containing two Co(II) atoms: Co1 and Co2, in which Co1 is six-coordinated by two nitrogen atoms from $\mathbf{L 1}$ and four oxygen atoms from two carboxylate ligands $\mathbf{H}_{2} \mathbf{L} 2$ in $\mu$ bridged mode, ${ }^{4 b}$ while Co2 forms an octahedral geometry by coordinating to two oxygen atoms from two carboxylate ligands $\mathbf{H}_{2} \mathbf{L} 2$, two oxygen atoms from two water molecules, and two nitrogen atoms from two $\mathbf{L 1}$ molecules, respectively. Subsequently, Co1 and Co2 are connected by two oxygen atoms from a carboxylate ligand, which further coordinate to $\mathrm{N}$ atoms form L1 to form a $2 \mathrm{D}$ structure. Interestingly, $\pi-\pi$ stacking interactions between anthracene rings can be observed with face to face distances of 3.5377-3.5661 $\AA$, which contribute to the formation of a 2D net structure (Fig. $1 \mathrm{~b}$ and $\mathrm{c}$ ). The structure of compound 1 can be simplified by topology program as a $2 \mathrm{D}$ square grid network with the point symbol of $\left\{4^{4} \cdot 6^{2}\right\}$ (Fig. 1d).

\section{$\left\{\left[\mathrm{Co}_{2}(\mathrm{L1})_{2}(\mathrm{L3})_{2} \cdot\left(\mathrm{H}_{2} \mathrm{O}\right)_{2}\right]_{n} \cdot 4 \mathrm{H}_{2} \mathrm{O}\right\}(2)$}

Structural analysis reveals that complex 2 belongs to a triclinic crystal system with the space group of $P \overline{1}$. Fig. 2 a shows the asymmetry unit of 2 contains two six-coordinated Co(II) cations (Co1 and Co2) with octahedral geometry, respectively, in which Co1 connects with four oxygen atoms from two L3 ligands and two nitrogen atoms from ligands L1, while Co2 coordinates to two oxygen atoms from two lattice water, two oxygen atoms form two carboxylate ligands and two $\mathrm{N}$ atoms from L1. Co1 and Co2 are bridged by carboxylate ligand, which further links to L1 ligands respectively to form a 2D network. Meanwhile, strong face to face $\pi-\pi$ stacking interactions between the anthracene rings can be observed with face to face distances of about 3.4946-3.5291 A, which may be favorably for the formation of 2D structure (Fig. 2b and c). Topological analysis shows complex 2 can be simplified as a 4-connected node $s q l$ with a Schläfli symbol of $\left\{4^{4} \cdot 6^{2}\right\}$ (Fig. 2d).

\section{$\left\{\left[\mathrm{Co}(\mathrm{L1})_{2}(\mathrm{HL} 3)_{2}\right]_{n} \cdot 2 \mathrm{CH}_{3} \mathrm{CN}\right\}$ (3)}

Single-crystal X-ray data shows that complex 3 crystallized in the monoclinic system with space group $P 2_{1} / c$. The secondary building unit (SBU) is consisted by two $\mathbf{H L 3}^{-}$, one Co(II) and four L1 ligands to present an octahedral geometry as depicted in Fig. 3a. The connections between Co(II) atoms and $\mathbf{L 1}$ further leads to the formation of a 2D network, in which extensive distorted face to face $\pi$-stacking interactions can be observed with contribution to the self-assembly of 2D supramolecular structure (face to face distances of about 3.8205 $\AA$ ) (Fig. 3b and c). Topologically, MOF 3 can be depicted as a 4-connected node with the point symbol $\left\{4^{4} \cdot 6^{2}\right\}$ (Fig. 3d). The coordination environment of $\mathrm{Co}(\mathrm{II})$ in SUB of MOF 3 is different to that of 2, providing the evidence for temperature-induced diversities of structure. 
Table 1 Crystallographic data for MOFs 1-4

\begin{tabular}{|c|c|c|c|c|}
\hline Compounds & 1 & 2 & 3 & 4 \\
\hline Formula & $\mathrm{C}_{76} \mathrm{H}_{62} \mathrm{Co}_{2} \mathrm{~N}_{8} \mathrm{O}_{13}$ & $\mathrm{C}_{76} \mathrm{H}_{60} \mathrm{Co}_{2} \mathrm{~N}_{8} \mathrm{O}_{14}$ & $\mathrm{C}_{80} \mathrm{H}_{56} \mathrm{CoN}_{10} \mathrm{O}_{8}$ & $\mathrm{C}_{56} \mathrm{H}_{40} \mathrm{CoN}_{4} \mathrm{O}_{10}$ \\
\hline fw & 1431.9 & 1427.18 & 1344.27 & 987.85 \\
\hline Temp., K & $293(2)$ & 293.15 & $293(2)$ & $293(2)$ \\
\hline Space group & $P \overline{1}$ & $P \overline{1}$ & $P 2_{1} / c$ & $P 2_{1} / n$ \\
\hline$a(\AA)$ & $10.353(4)$ & $10.336(8)$ & $14.1122(9)$ & $13.407(6)$ \\
\hline$b(\AA)$ & $12.285(6)$ & $12.301(10)$ & $27.0471(18)$ & $12.528(4)$ \\
\hline$\beta$ (deg) & $107.318(10)$ & $107.255(19)$ & $108.227(2)$ & 114.216(19) \\
\hline$\gamma(\mathrm{deg})$ & $107.004(13)$ & $107.055(19)$ & 90 & 90 \\
\hline$V\left(\AA^{3}\right)$ & $1588.1(11)$ & $1587(2)$ & $3320.7(4)$ & $2382(2)$ \\
\hline$Z$ & 1 & 1 & 2 & 2 \\
\hline$D_{\mathrm{c}}\left(\mathrm{g} \mathrm{cm}^{-3}\right)$ & 1.478 & 1.493 & 1.344 & 1.377 \\
\hline$\mu\left(\mathrm{mm}^{-1}\right)$ & 0.599 & 0.601 & 0.326 & 0.427 \\
\hline$R_{1}^{a}, \mathrm{w}_{2}{ }^{b}$ (all data) & $0.0439 / 0.0876$ & $0.0668 / 0.1307$ & $0.0644 / 0.1035$ & $0.0773 / 0.1099$ \\
\hline Largest peak, hole $\left(\mathrm{e}^{\mathrm{A}}{ }^{-3}\right)$ & $0.30 /-0.33$ & $0.81 /-0.62$ & $0.41 /-0.30$ & $0.23 /-0.34$ \\
\hline
\end{tabular}

${ }^{a} R_{1}=\sum|| F_{\mathrm{o}}|-| F_{\mathrm{c}}|| / \sum\left|F_{\mathrm{o}}\right| \cdot{ }^{b} \mathrm{w} R_{2}=\sum\left[\mathrm{w}\left(F_{\mathrm{o}}{ }^{2}-F_{\mathrm{c}}{ }^{2}\right)^{2}\right] / \sum\left[\mathrm{w}\left(F_{\mathrm{o}}{ }^{2}\right)^{2}\right]^{1 / 2}$.

\section{$\left\{\left[\mathrm{Co}(\mathrm{L1})(\mathrm{HL} 3)_{2} \cdot\left(\mathrm{H}_{2} \mathrm{O}\right)_{2}\right]_{n}\right\}(4)$}

Structural analysis shows that complex $\mathbf{4}$ is a monoclinic crystal system, space group $P 2_{1} / n$. The asymmetric SBU has a six coordinated $\mathrm{Co}$ (II) core connecting with two $\mathrm{O}$ atoms from two HL3 ligands, two $\mathrm{N}$ atoms form two $\mathrm{L1}$ and two $\mathrm{O}$ atoms from two lattice water molecules to form a octahedral geometry (Fig. 4a), in which the another $\mathrm{N}$ atom of imidazole in $\mathbf{L 1}$ further coordinates to $\mathrm{Co}(\mathrm{II})$ in next $\mathrm{SBU}$, forming a 1D chain structure (Fig. 4b and c), further suggesting the key role of temperature in the synthesis of MOF.

It is worth noting that ligands variation in synthetic processes lead to a slight pore size change from micropore in $\mathbf{1}$ to mesoporous in $\mathbf{2}$, which may due to the more rigid dibenzobarrelene derived carboxylate ligand $\mathbf{H}_{2} \mathbf{L} \mathbf{3}$ (bridgehead $\mathrm{C}=\mathrm{C}$ ) compared to that of $\mathbf{H}_{2} \mathbf{L} 2$ (bridgehead $\mathrm{C}-\mathrm{C}$ ), while no other
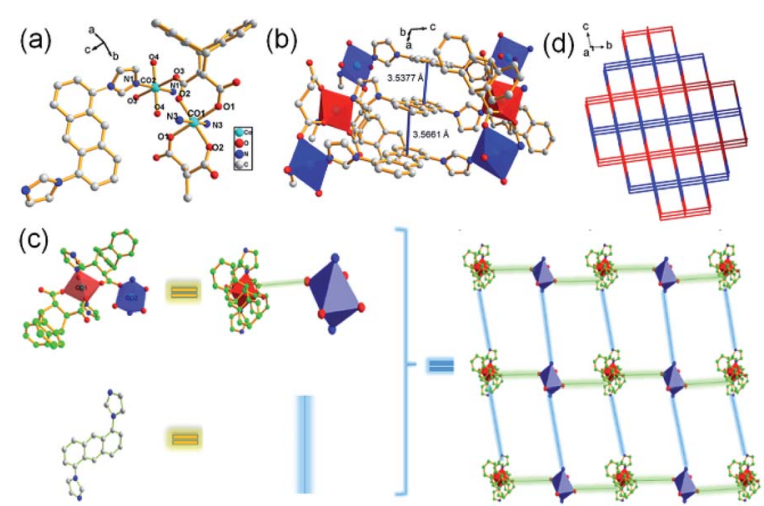

Fig. 1 (a) Asymmetric unit of 1 , symmetry code: (i) $=1-x, 1-y, 1-z$; (ii) $=2-x, 1-y, 1-z$; (iii) $=2-x, 1-y, 2-z$; (iv) $=1-x, 1-y,-z$; (b) $\pi$-stacking interactions in 1 ; (c) simplified $2 \mathrm{D}$ structure of 1 ; (d) topology structure of 1 . obvious structural changes between them can be observed. However, temperature controlled strategies employed in synthetic processes of MOFs 2-4 causes the distinct coordination environment of $\mathrm{Co}(\mathrm{II})$ (two coordination modes of dibenzobarrelene derived carboxylate ligands as depicted in Scheme $\mathrm{S} 2 \dagger)$ as well as the transformation from $2 \mathrm{D}$ porous structure $(2$ and 3) to 1D chain structure (4) with a gradual rise in temperature. The above mentioned results imply the important roles of ligands/temperature in tailoring structure of MOFs.

\section{PXRD, TGA and $\mathrm{N}_{2}$ adsorption}

Fig. S5 $\uparrow$ shows the experimental PXRD patterns of MOFs 1-4 closely match that simulated patterns obtained from the single crystal data, demonstrating the phase purity of as-synthesized MOFs. As depicted in Fig. S6, $\dagger$ TG curves for 1-4 were

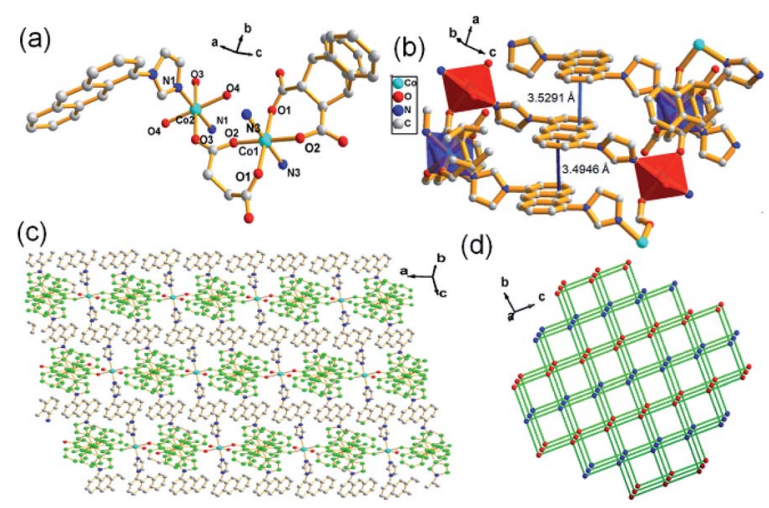

Fig. 2 (a) Asymmetric unit of 2, symmetry code: (i) $=2-x, 1-y, 2-z$; (ii) $=1-x, 1-y, 2-z$; (iii) $=1-x, 1-y, 1-z$; (iv) $=2-x, 1-y, 1-z$; (b) $\pi$-stacking interactions between the anthracene rings in 2; (c) $2 \mathrm{D}$ structure of 2; (d) topological analysis of 2 . 


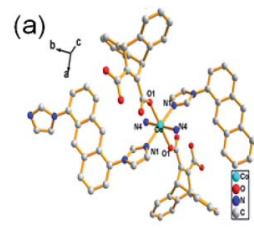

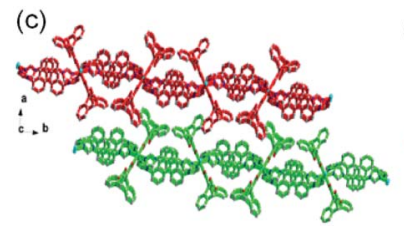

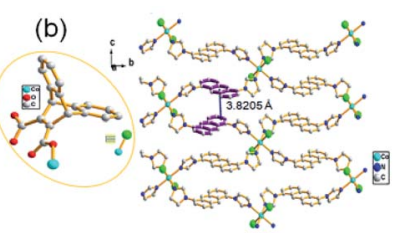

(d)

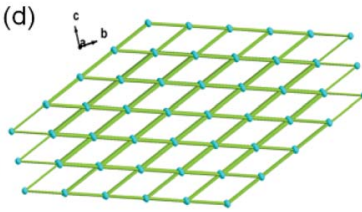

Fig. 3 (a) The SBU of 3, symmetry code: (i) $=-x, 1-y,-z$; (ii) $=+x, 3 / 2$ $-y, 1 / 2+z$; (iii) $=-x,-1 / 2+y,-1 / 2-z$; (iv) $=-x, 1 / 2+y,-1 / 2-z$; (b) infinite 2D layer of 3 ; (c) stack-configuration of 3 ; (d) topological architecture of 3 .

recorded in the temperature range of $35-600{ }^{\circ} \mathrm{C}$ to evaluate the stability of samples. Based on the thermogravimetric analysis, complex 1 loses $2.8 \%$ (calcd $2.5 \%$ ) weight from $150-180{ }^{\circ} \mathrm{C}$ associated with the loss of crystallization water, which begins to collapse beyond $c a .270^{\circ} \mathrm{C}$. Complex 2 has a weight loss of $3.3 \%$ (calcd $2.5 \%$ ) from $100-228{ }^{\circ} \mathrm{C}$, corresponding to the water molecules, and then decomposes around $270{ }^{\circ} \mathrm{C}$. A weight loss of $6.7 \%$ (calcd $6.1 \%$ ) is observed when complex 3 is heated from $35-270{ }^{\circ} \mathrm{C}$, which should be ascribed to the escape of residual acetonitrile molecule, and a structural decomposition occurs at about $280{ }^{\circ} \mathrm{C}$. For complex 4 , it exhibits a weight loose of $3.5 \%$ (calcd $3.6 \%$ ) between $100-250{ }^{\circ} \mathrm{C}$ corresponding to the lattice water, which begins to collapse at around $251{ }^{\circ} \mathrm{C}$. The results demonstrate the good stability of these samples. In addition, the porous structures of 1-3 were evaluated by $\mathrm{N}_{2}$ adsorption at 77 K. Fig. S7† shows BET surface areas of complex 1-3 are estimated to be $13.694 \mathrm{~m}^{2} \mathrm{~g}^{-1}, 10.485 \mathrm{~m}^{2} \mathrm{~g}^{-1}$ and $4.194 \mathrm{~m}^{2} \mathrm{~g}^{-1}$, respectively. Meanwhile, the pore diameters of them are calculated to be $1.754 \mathrm{~nm}, 2.000 \mathrm{~nm}$, and $3.502 \mathrm{~nm}$, respectively.

\section{Sensing behaviors towards nitrobenzene}

To understand the luminescent behaviors of MOFs 1-4, $0.3 \mathrm{mg}$ of them were added respectively into $3 \mathrm{~mL}$ suitable solvents and ultrasonated for $0.5 \mathrm{~h}$ to obtain dispersed suspensions. Firstly, the emission profiles of 1-4 were investigated in different solvents. Fig. S8† show all samples present obvious emission peaks centered at the range of 400-430 nm, while they show almost completely quenching phenomena with nearly $100 \%$ quenching efficiency in NB, which is analogues to that of most
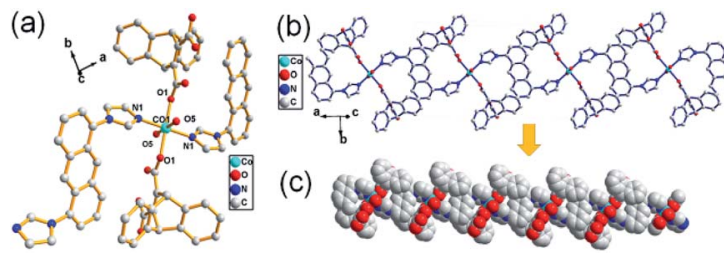

Fig. 4 (a) The SBU of 4 , symmetry code: (i) $=1-x,-y, 1-z$; (ii) $=-x$, $-y, 1-z ;$ (b) 1D chain structure of 4 ; (c) stacking diagram of 4 . reported MOFs. ${ }^{11 i-m}$ Though a slight solvation effect for the wavelength can be observed with different solvents polarity, suggesting solvent-dependence of the emission intensity, no obvious relationship between them can be found. Secondly, to further investigate the selectivity of these MOFs towards NB among various NACs, water was chosen as detection medium for its environment friendliness. Then the specific responses of MOFs towards nitrobenzene among various NACs were examined in water under $270 \mathrm{~nm}$ excitation by fluorescence spectra, in which the suspension solutions of 1-4 were added with equivalents of different NACs including NB, 4-hydroxynitrobenzene (4-NP), 2,4,6-trinitrophenol (TNP), 2-nitrophenol (2$\mathrm{NP})$, 1-chloro-4-nitrobenzene (4-CNB), 4-nitrotoluene (4-NTol), 2-nitro-phenylamine (2-NPA), 3-nitrophenol (3-NP), 2,4-dinitroaniline (2,4-DNA), 4-nitroaniline (4-NPA), 2,4-dinitrophenylhydrazine (2,4-NPH) and 4-nitrobenzoic acid (4-NBA). Fig. $\mathrm{S} 9 \dagger$ and 5 show samples 1-4 exhibit obvious fluorescence bands centered at $c a .425 \mathrm{~nm}$, and the addition of low concentrations $\left(1.7 \times 10^{-5} \mathrm{~mol} \mathrm{~L}^{-1}\right)$ of $\mathrm{NB}$ causes significant decreases in fluorescence intensity at $425 \mathrm{~nm}$ with quenching efficiencies of $60.0 \%, 76.6 \%, 75.5 \%$ and $68.3 \%$ for MOFs 1-4, respectively, while the other NACs only elicit slight decreases in emission intensity with quenching efficiency less than $20 \%$. The results indicate all MOFs show high selectivity towards nitrobenzene compared with that of other MOF-based sensors in Table S1, $\dagger$ which may be ascribed to PET process from the ligands to NB. ${ }^{11 a}$ In addition, the effect of other NACs for the specific responses of MOFs 1-4 towards NB were evaluated by competition experiments, in which the fluorescence profiles were obtained from the chemosensors solutions in the presence of various NACs coexisting with NB, respectively. Fig. 6 exhibits other NACs causes no obvious fluorescence changes of 1-4 compared to that of NB alone, further suggesting the high selectivity of these MOFs towards NB. To better understand the sensing behaviors of 1-4 towards NB, the fluorescence titration assays of them were recorded by treatment of increasing concentrations of NB, respectively. As can be seen from Fig. 7, low concentration of NB $(3.3 \mu \mathrm{M})$ can trigger obvious fluorescence changes for all samples, indicating their sensitivities towards NB. Overall, the fluorescence intensity of all MOFs

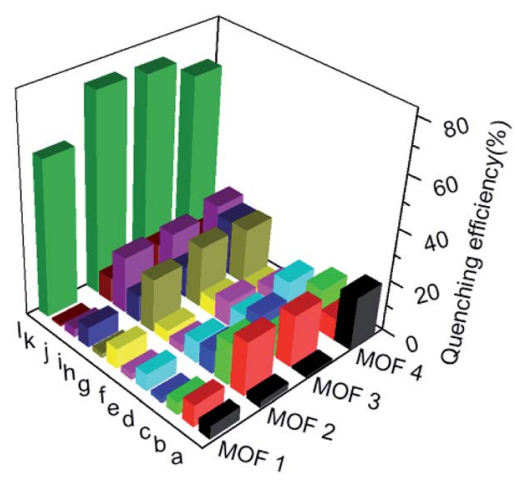

Fig. 5 Emission quenching efficiencies of 1-4 in water after the addition of various NACs $(16.7 \mu \mathrm{M})$. Histograms $(a)-(l)$ represent: 4-NP; TNP; 2-NP; 4-CNB; 4-NTol; 2-NPA; 3-NP; 2,4-DNA; 4-NPA; 2,4$\mathrm{NPH} ; 4-\mathrm{NBA}$ and NB, respectively. 


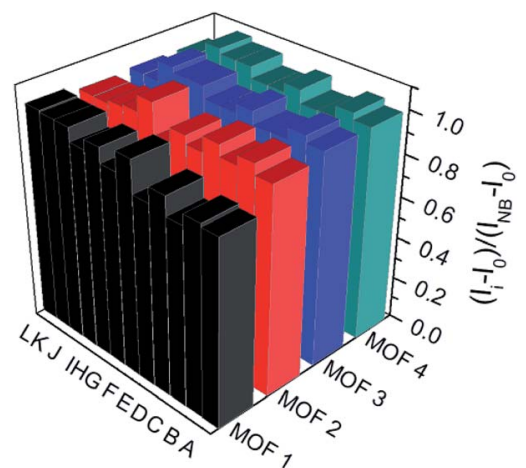

Fig. 6 Emission intensity ratio changes of MOFs $1-4$ towards NB (16.7 $\mu \mathrm{M})$ and $\mathrm{NB}(16.7 \mu \mathrm{M})$ in presence of equivalent other NACs. Histogram (A) - (L) represent: NB + 4-NP; NB + TNP; NB + 2-NP; NB + 4-CNB; NB + 4-NTol; NB alone; NB + 2-NPA; NB + 3-NP; NB + 2, 4-DNA; NB + 4$\mathrm{NPA} ; \mathrm{NB}+2,4-\mathrm{NPH}$ and NB + 4-NBA, respectively.

sharply decreases with the addition of NB below the concentrations of $c a .16 .7 \mu \mathrm{M}$ and completely quenches at high concentration of $\mathrm{NB}(c a .70 \mu \mathrm{M})$ with quenching efficiencies beyond $96 \%$. The fluorescence quenching efficiency is evaluated via Stern-Volmer formula $\left(I_{0} / I\right)=K_{\mathrm{sv}}[\mathrm{NB}]+1$, where $I_{0}$ and $I$ represent the fluorescence intensity before and after addition of an NB, respectively; ([NB] refers to the concentration of NB, and $K_{\mathrm{sv}}$ is the quenching constant). Fig. $\mathrm{S} 9 \dagger$ shows a linear increase in the $\mathrm{S}-\mathrm{V}$ plots at the low concentrations of $\mathrm{NB}$, while the further increasing concentration causes divergences from the linearity, which could be probably ascribed to an analogous diffusion-controlled energy transfer process reported in literature. ${ }^{11 l}$ Moreover, the $K_{\mathrm{sv}}$ values of $\mathbf{1 - 4}$ for NB are evaluated as $4.59 \times 10^{4} \mathrm{M}^{-1}, 6.15 \times 10^{4} \mathrm{M}^{-1}, 3.28 \times 10^{4} \mathrm{M}^{-1}$ and $4.50 \times 10^{4}$ $\mathbf{M}^{-1}$, respectively, which are larger than that in the previous literatures. ${ }^{11 j, k}$ Besides, MOFs 1-4 can be renewable and reused for four numbers of cycles via centrifugation, filtration and rinsing several times with DMF, which show insignificant
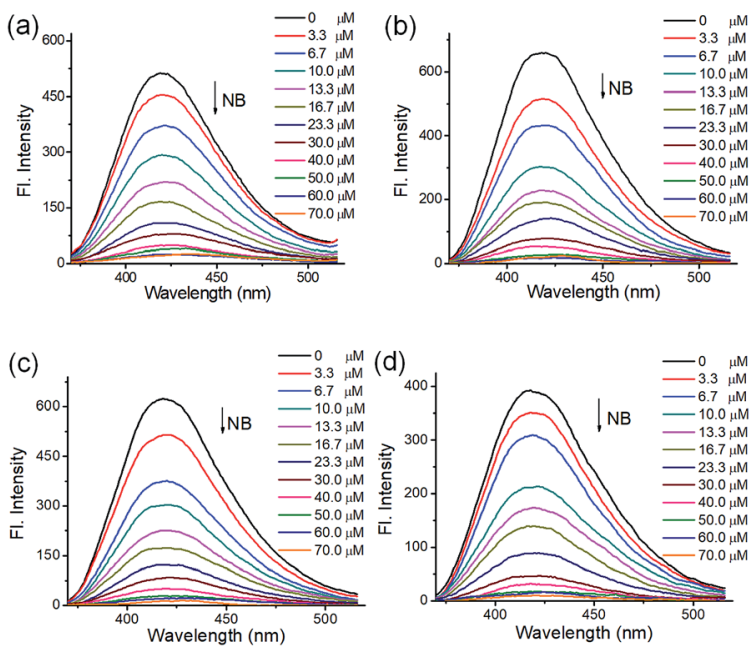

Fig. 7 Emission profiles of MOFs ( $(a-d)$ for 1-4, respectively) upon treatment of different concentrations of NB $(0-70 \mu \mathrm{M})$ in water, $\lambda_{\text {ex }}$ : $270 \mathrm{~nm}$. quenching efficiency decreases after four repeated cycles, suggesting the stability and recyclability of MOFs 1-4 in detection of NB (Fig. S11†).

Considering either the porous frameworks of 1-3 $(1.754 \mathrm{~nm}$, $2.000 \mathrm{~nm}$ and $3.502 \mathrm{~nm}$ for 1-3, respectively) or 1D structure of 4 could provide suitable pores for inclusion of NB molecule (6.0 $\AA)$, the possible quenching mechanism is suggested to be the electron transfer processes from the electron donating ligands to the electron deficient NB molecules that adhered to the surface of MOFs. ${ }^{18}$ With the above idea in mind as well as to further illustrate the specific response mechanisms of MOFs 14 to $\mathrm{NB}$, the fluorescence quenching mechanism was examined at the level of B3LYP/6-31G* according to density functional theory. Fig. 8 shows the LUMO $(-3.1026 \mathrm{eV})$ of NB is lower than that of ligands $\mathbf{H}_{2} \mathbf{L} 2, \mathbf{H}_{2} \mathbf{L} 3$ and $\mathbf{L 1}(-0.9954 \mathrm{ev},-2.3454 \mathrm{ev}$ and $-1.1685 \mathrm{ev}$, respectively), which is favorable for electron transfer from the excited state of ligands to that of NB, resulting in luminescence quenching behaviors. As state above, all prepared MOF samples exhibit high selectivity towards NB via PET mechanism controlled fluorescence quenching process.

\section{Electrocatalytic OER}

Electrocatalytic properties of MOFs 1-4 were investigated. Fig. 9a shows the polarization curves of all as-synthesized samples obtained by LSV measurements, in which 1-4 present electrocatalytic OER activities with onset overpotentials of 354 , 352,373 and $345 \mathrm{mV}$, and overpotentials of 411, 406, 438 and $398 \mathrm{mV}$ for achieving current density of $10 \mathrm{~mA} \mathrm{~cm}{ }^{-2}\left(\eta_{10}\right)$, respectively. The results could compare favorably to those of OER catalysts in reported works (Table S3†). ${ }^{14 d, e}$ Fig. 9b shows OER kinetics of MOFs 1-4 are characterized with Tafel plots of $58,62,60$, and $59 \mathrm{mV} \mathrm{dec}{ }^{-1}$, respectively, revealing a more favorable kinetics of $\mathbf{4}$ for electrocatalytic OER. Next, electrochemical impedance spectroscopy (EIS) was conducted to evaluate the electrode activities for OER under operating conditions. As shown in Fig. S12, $\uparrow$ all MOFs deliver more than one semicircles in the Nyquist curves. The low frequency loop may be attributed to the adsorption on the electrode surface of reaction intermediate such as $\mathrm{O}_{\mathrm{ad}}$ as reported in literature, ${ }^{14 e}$ and the high frequency loop corresponds to charge transfer

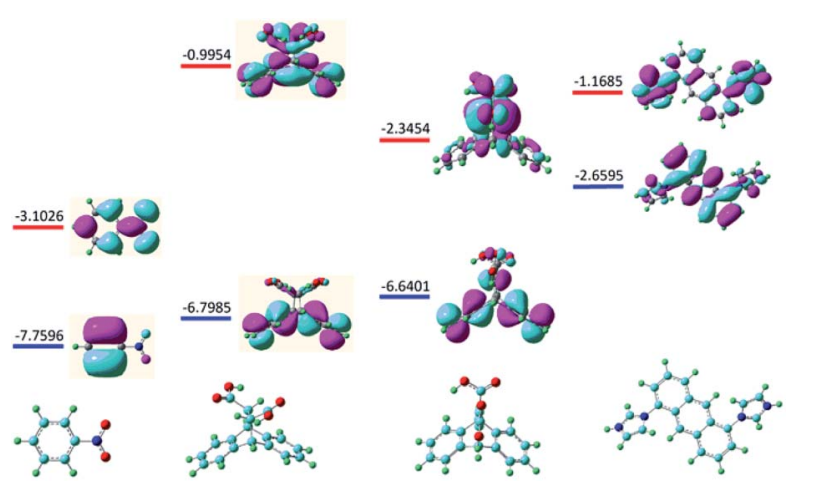

Fig. 8 Optimal structures and calculated HOMO (blue) and LUMO (red) orbits for NB and ligands $\mathrm{H}_{2} \mathrm{~L} 2, \mathrm{H}_{2} \mathrm{~L} 3$ and L1. 

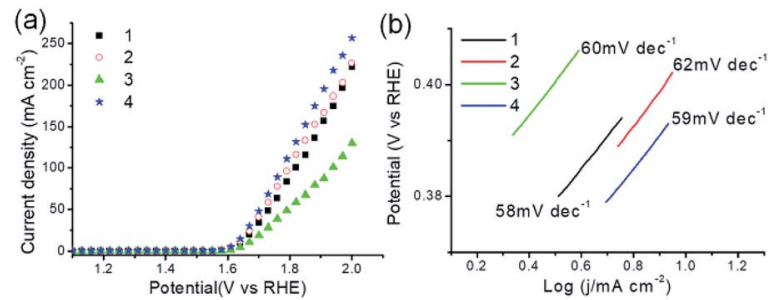

Fig. 9 (a) OER polarization curves of as-synthesized MOFs 1-4 in $1 \mathrm{M}$ $\mathrm{KOH}$ solution with a scan rate of $5 \mathrm{mV} \mathrm{s}^{-1}$. (b) Tafel plots of 1-4.

processes. Among them, 4 holds the smallest value of chargetransfer resistance $\left(R_{\mathrm{ct}}\right)$, revealing the fastest electron transfer property and high electrocatalytic activity toward oxygen production under the catalysis of $\mathbf{4}$. Furthermore, the PXRD patterns of 1-4 immersed in $1 \mathrm{M} \mathrm{KOH}$ for $2 \mathrm{~h}$ were acquired. As provided in Fig. $\mathbf{S 1 3}, \uparrow$ the PXRD patterns of all samples remain almost unchanged, suggesting their retained crystallinity and stabilities. As described, MOFs 1-4 exhibit promising activities for electrocatalytic OER.

\section{Conclusions}

In conclusion, four 2D/1D Co-MOFs have been designed and obtained with structural diversities based on 1,5-biimidazoylanthracene and different dibenzobarrelene skeletons derived dicarboxylic acid, among which 1-3 show 2D network in a 4connected node $s q l$ with the point symbols of $\left\{4^{4} \cdot 6^{2}\right\}$ and 4 presents a 1D chain structure. Notably, strategy of varying temperature to tailor the structures of MOFs have been adopted and realized in the synthesis of 2-4, suggesting the key role of temperature in constructing MOFs. In addition, MOFs 1-4 exhibit high selectivity and sensitivity towards NB among various nitro-aromatics compounds in water, which is confirmed to be a result of electron transfer from the excited state of ligands to that of NB by density functional theory. Besides, MOFs 1-4 can be directly used as electrocatalysts for OER and 4 exhibits the best activity among all as-synthesized samples with low overpotential of $398 \mathrm{mV}$ to achieve current density of $10 \mathrm{~mA} \mathrm{~cm}{ }^{-2}$ and Tafel slope of $59 \mathrm{mV} \mathrm{dec}^{-1}$. This work is of great importance for extensively developing structural diversity MOFs via temperature regulation and employing MOFs as efficiently sensing and electrocatalytic materials.

\section{Conflicts of interest}

There are no conflicts to declare.

\section{Acknowledgements}

This work was financially supported by the National Natural Science Foundation of China (21671159), Meritocracy Research Funds of China West Normal University (17YC030, 17YC010), Sichuan Provincial Education Department (18ZA0470), Chengdu University of Technology Teacher Development Fund (10912-2019KYQD-07546).

\section{Notes and references}

1 (a) M. Eddaoudi, H. Li and O. M. Yaghi, J. Am. Chem. Soc., 2000, 122, 1391-1397; (b) X. C. Huang, Y. Y. Lin, J. P. Zhang and X. M. Chen, Angew. Chem., Int. Ed., 2006, 45, 1557-1559; (c) O. K. Farha, I. Eryazici, N. C. Jeong, B. G. Hauser, C. E. Wilmer, A. A. Sarjeant, R. Q. Snurr, S. T. Nguygn, A. O. Yazaydin and J. T. Hupp, J. Am. Chem. Soc., 2012, 134, 15016-15021; (d) J. Pang, S. Yuan, J. Qin, C. Liu, C. Lollar, M. Wu, D. Yuan, H. C. Zhou and M. Hong, J. Am. Chem. Soc., 2017, 139, 16939-16945; (e) X. Gu and D. Xue, CrystEngComm, 2007, 9, 471-477.

2 (a) H. Furukawa, K. E. Cordova, M. O'Keeffe and O. M. Yaghi, Science, 2013, 341, 1230444; (b) B. Chen, N. W. Ockwig, A. R. Millward, D. S. Contreras and O. M. Yaghi, Angew. Chem., Int. Ed., 2005, 44, 4745-4749; (c) Z. Zhou, C. He, J. Xiu, L. Yang and C. Duan, J. Am. Chem. Soc., 2015, 137, 15066-15069; (d) P. Horcajada, R. Gref, T. Baati, P. K. Allan, G. Maurin, P. Couvreur, C. Férey, R. E. Morris and C. Serre, Chem. Rev., 2012, 112, 1232-1268; (e) M. X. Wu and Y. W. Yang, Adv. Mater., 2017, 29, 1606134; (f) J. Park, Q. Jiang, D. Feng, L. Mao and H. C. Zhou, J. Am. Chem. Soc., 2016, 138, 3518-3525; $(g)$ S. Khatua, S. Goswami, S. Biswas, K. Tomar, H. S. Jena and S. Konar, Chem. Mater., 2015, 27, 5349-5360; (h) J. X. Hou, J. P. Gao, J. Liu, X. Jing, L. J. Li and J. L. Du, Dyes Pigm., 2019, 160, 159-164; (i) G. Xiong, B. Yu, J. Dong, Y. Shi, B. Zhao and L. N. He, Chem. Commun., 2017, 53, 6013-6016.

3 (a) L. Luo, P. Wang, G. C. Xu, Q. Liu, K. Chen, Y. Lu, Y. Zhao and W. Y. Sun, Cryst. Growth Des., 2012, 12, 2634-2645; (b) H. J. Lee, P. Y. Cheng, C. Y. Chen, J. S. Shen, D. Nandi and H. M. Lee, CrystEngComm, 2011, 13, 4814-4816; (c) Z. Wei, Z. Y. Gu, R. K. Arvapally, Y. P. Chen, R. N. McDougald Jr, J. F. Ivy, A. A. Yakovenko, D. Feng, M. A. Omary and H. C. Zhou, J. Am. Chem. Soc., 2014, 136, 8269-8276; (d) J. Pang, C. Liu, Y. Huang, M. Wu, F. Jiang, D. Yuan, F. Hu, K. Su, G. Liu and M. Hong, Angew. Chem., Int. Ed., 2016, 55, 7478-7482; (e) M. Zhang, Z. Qi, Y. Feng, B. Guo, Y. Hao, Z. Xu, L. Zhang and D. Sun, Inorg. Chem. Front., 2018, 5, 1314-1320; $(f)$ A. K. Crane, N. G. White and M. J. MacLachlan, CrystEngComm, 2015, 17, 4912-4918; $(g)$ T. Wang, K. Huang, M. Peng, X. Li, D. Han, L. Jing and D. Qin, CrystEngComm, 2019, 21, 494-501.

4 (a) W. G. Yuan, F. Xiong, H. L. Zhang, W. Tang, S. F. Zhang, Z. He, L. Jing and D. Qin, CrystEngComm, 2014, 16, 77017710; (b) Y. Liang, W. G. Yuan, S. F. Zhang, Z. He, J. Xue, X. Zhang, L. Jing and D. Qin, Dalton Trans., 2016, 45, 13821390; (c) C. H. Ke, G. R. Lin, B. C. Kuo and H. M. Lee, Cryst. Growth Des., 2012, 12, 3758-3765; (d) S. Q. Zang, M. M. Dong, Y. J. Fan, H. W. Hou and T. C. Mak, Cryst. Growth Des., 2012, 12, 1239-1246; (e) S. F. Zhang, F. Xiong, Z. He, Y. Liang, J. R. Xue, L. H. Jing and D. B. Qin, Polyhedron, 2015, 102, 401-409; (f) S. Mukherjee, D. Samanta and P. S. Mukherjee, Cryst. Growth Des., 2013, 13, 5335-5343; $(g)$ L. Luo, S. Q. Liu, X. W. Xu, J. Xu and J. L. Zhao, CrystEngComm, 2018, 20, 7719-7728. 
5 (a) B. Liu, L. Wei, N. N. Li, W. P. Wu, H. Miao, Y. Y. Wang and Q. Z. Shi, Cryst. Growth Des., 2014, 14, 1110-1127; (b) H. F. Zhou, T. He, K. F. Yue, Y. L. Liu, C. S. Zhou, N. Yan and Y. Y. Wang, Cryst. Growth Des., 2016, 16, 3961-3968; (c) L. Y. Du, H. Wang, G. Liu, D. Xie, F. S. Guo, L. Hou and Y. Y. Wang, Dalton Trans., 2015, 44, 1110-1119; (d) B. Zheng, H. Dong, J. Bai, Y. Li, S. Li and M. Scheer, J. Am. Chem. Soc., 2008, 130, 77787779; (e) Y. B. Dong, Y. Y. Jiang, J. Li, J. P. Ma, F. L. Liu, B. Tang, R. Q. Huang and S. R. Batten, J. Am. Chem. Soc., 2007, 129, 4520-4521; $(f)$ K. L. Gurunatha, K. Uemura and T. K. Maji, Inorg. Chem., 2008, 47, 6578-6580; (g) P. Cui, L. Ren, Z. Chen, H. Hu, B. Zhao, W. Shi and P. Cheng, Inorg. Chem., 2012, 51, 2303-2310; (h) X. Y. Duan and M. L. Wei, Cryst. Growth Des., 2017, 17, 1197-1207; (i) J. J. Hou, X. Q. Li, P. Gao, H. Q. Sun and X. M. Zhang, Cryst. Growth Des., 2017, 17, 3724-3730; (j) Y. F. Hou, B. Liu, K. F. Yue, C. S. Zhou, Y. M. Wang, N. Yan and Y. Y. Wang, CrystEngComm, 2014, 16, 9560-9567.

6 (a) Z. He, K. Huang, F. Xiong, S. F. Zhang, J. R. Xue, Y. Liang, L. H. Jing and D. B. Qin, J. Organomet. Chem., 2015, 797, 6775; (b) X. J. Li, Z. J. Yu, T. N. Guan, X. X. Li, G. C. Ma and X. F. Guo, Cryst. Growth Des., 2014, 15, 278-290.

7 (a) M. Eddaoudi, J. Kim, N. Rosi, D. Vodak, J. Wachter, M. O'Keeffe and O. M. Yaghi, Science, 2002, 295, 469-472; (b) N. B. Shustova, A. F. Cozzolino and M. Dincă, J. Am. Chem. Soc., 2012, 134, 19596-19599.

8 M. Zhang, L. Zhang, Z. Xiao, Q. Zhang, R. Wang, F. Dai and D. Sun, Sci. Rep., 2016, 6, 20672.

9 (a) Z. Hu, B. J. Deibert and J. Li, Chem. Soc. Rev., 2014, 43, 5815-5840; (b) W. P. Lustig, S. Mukherjee, N. D. Rudd, A. V. Desai, J. Li and S. K. Ghosh, Chem. Soc. Rev., 2017, 46, 3242-3285; (c) Y. Zhang, S. Yuan, G. Day, X. Wang, X. Yang and H. C. Zhou, Coord. Chem. Rev., 2018, 354, 28-45.

10 (a) S. S. Nagarkar, B. Joarder, A. K. Chaudhari, S. Mukherjee and S. K. Ghosh, Angew. Chem., Int. Ed., 2013, 52, 2881-2885; (b) C. Wang, J. Shang, Y. Lan, T. Tian, H. Wang, X. Chen, J. Y. Gu, J. Z. Liu, L. J. Wan, W. Zhu and G. Li, Adv. Funct. Mater., 2015, 25, 6009-6017; (c) M. Bagheri, M. Y. Masoomi, A. Morsali and A. A. Schoedel, ACS Appl. Mater. Interfaces, 2016, 8, 21472-21479; (d) R. B. Fu, S. M. Hu and X. T. Wu, J. Mater. Chem. A, 2017, 5, 1952-1956.

11 (a) S. Pramanik, C. Zheng, X. Zhang, T. J. Emge and J. Li, J. Am. Chem. Soc., 2011, 133, 4153-4155; (b) J. H. Qin, B. Ma, X. F. Liu, H. L. Lu, X. Y. Dong, S. Q. Zang and H. Hou, Dalton Trans., 2015, 44, 14594-14603; (c) W. Xie, S. R. Zhang, D. Y. Du, J. S. Qin, S. J. Bao, J. Li, Z. M. Su, W. W. He, Q. Fu and Y. Q. Lan, Inorg. Chem., 2015, 54, 3290-3296; (d) L. Li, S. Zhang, L. Xu, L. Han, Z. N. Chen and J. Luo, Inorg. Chem., 2013, 52, 12323-12325; (e) L. Di, J. J. Zhang, S. Q. Liu, J. Ni, H. Zhou and Y. J. Sun, Cryst. Growth Des., 2016, 16, 4539-4546; (f) S. Zhang, L. Han, L. Li, J. Cheng, D. Yuan and J. Luo, Cryst. Growth Des., 2013, 13, 5466-5472; (g) X. Zhou, H. Li, H. Xiao, L. Li, Q. Zhao, T. Yang, J. Zuo and W. Huang, Dalton Trans., 2013, 42, 5718-5723; (h) Y. N. Gong, L. Jiang and T. B. Lu, Chem. Commun., 2013, 49, 11113-11115; ( $i$ ) G. Y. Wang, L. L. Yang, Y. Li, H. Song, W. J. Ruan, Z. Chang and X. H. Bu, Dalton Trans., 2013, 42, 12865-12868; (j)
R. X. Yao, X. Cui, X. X. Jia, F. Q. Zhang and X. M. Zhang, Inorg. Chem., 2016, 55, 9270-9275; (k) Y. T. Yan, J. Liu, G. P. Yang, F. Zhang, Y. K. Fan, W. Y. Zhang and Y. Y. Wang, CrystEngComm, 2018, 20, 477-486; (l) D. M. Chen, X. Z. Ma, W. Shi and P. Cheng, Cryst. Growth Des., 2015, 15, 3999-4004; (m) D. Liu, X. Liu, Y. Liu, Y. Yu, F. Chen and C. Wang, Dalton Trans., 2014, 43, 15237-15244. 12 C. Tan and H. Zhang, Chem. Soc. Rev., 2015, 44, 2713-2731. 13 (a) S. Piccinin, A. Sartorel, G. Aquilanti, A. Goldoni, M. Bonchio and S. Fabris, Proc. Natl. Acad. Sci. U. S. A., 2013, 110, 4917-4922; (b) W. Zhang and K. Zhou, Small, 2017, 13, 1700806; (c) S. Wang, Y. Hou, S. Lin and X. Wang, Nanoscale, 2014, 6, 9930-9934.

14 (a) J. Q. Sheng, P. Q. Liao, D. D. Zhou, C. T. He, J. X. Wu, W. X. Zhang, J. P. Zhang and X. M. Chen, J. Am. Chem. Soc., 2017, 139, 1778-1781; (b) Y. T. Xu, Z. M. Ye, J. W. Ye, L. M. Cao, R. K. Huang, J. X. Wu, D. D. Zhou, X. F. Zhang, C. T. He, J. P. Zhang and X. M. Chen, Angew. Chem., Int. Ed., 2019, 131, 145-149; (c) J. Duan, S. Chen and C. Zhao, Nat. Commun., 2017, 8, 15341; (d) F. Dai, W. Fan, J. Bi, P. Jiang, D. Liu, X. Zhang, H. Lin, C. Gong, R. Wang, L. Zhang and D. Sun, Dalton Trans., 2016, 45, 61-65; (e) J. Jiang, L. Huang, X. Liu and L. Ai, ACS Appl. Mater. Interfaces, 2017, 9, 7193-7201; $(f)$ X. Zhao, B. Pattengale, D. Fan, Z. Zou, Y. Zhao, J. Du, J. Huang and C. Xu, ACS Energy Lett., 2018, 3, 2520; (g) J. Li, W. Huang, M. Wang, S. Xi, J. Meng, K. Zhao, J. Jin, W. Xu, Z. Wang, X. Liu, Q. Chen, L. Xu, X. Liao, Y. Jiang, A. K. Owusu, B. Jing, C. Chen, D. Fan, L. Zhou and L. Mai, ACS Energy Lett., 2018, 4, 285-292; (h) Z. Xue, Y. Li, Y. Zhang, W. Geng, B. Jia, J. Tang, S. Bao, H. Wang, Y. Fan, Z. Wei, Z. Zhang, Z. Ke, G. Li and C. Su, Adv. Energy Mater., 2018, 8, 1801564; (i) F. L. Li, Q. Shao, X. Huang and J. P. Lang, Angew. Chem., Int. Ed., 2018, 57, 1888-1892; (j) W. Zhou, D. D. Huang, Y. P. Wu, J. Zhao, T. Wu, J. Zhang, D. S. Li, C. Su, P. Feng and X. Bu, Angew. Chem., Int. Ed., 2019, 58, 1-6; (k) G. Hai, X. Jia, K. Zhang, X. Liu, Z. Wu and G. Wang, Nano Energy, 2018, 44, 345-352; (l) S. Zhao, Y. Wang, J. Dong, C. T. He, H. Yin, P. An, K. Zhao, X. Zhang, C. Gao, L. Zhang, J. Lv, J. Wang, J. Zhang, A. M. Khattak, N. A. Khan, Z. Wei, J. Zhang, S. Liu, H. Zhao and Z. Tang, Nat. Energy, 2016, 1, 16184; (m) K. Wan, J. Luo, C. Zhou, T. Zhang, J. Arbiol, X. Lu, B. W. Mao, X. Zhang and J. Fransaer, Adv. Funct. Mater., 2019, 29, 1900315; (n) X. Zhang, J. Luo, K. Wan, D. Plessers, B. Sels, J. Song, L. Chen, T. Zhang, P. Tang, J. R. Morante, J. Arbiol and J. Fransaer, J. Mater. Chem. A, 2019, 7, 1616-1628.

15 İ. Çapan and S. Servi, Synth. Commun., 2018, 48, 1164-1171. 16 G. M. Sheldrick, Acta Crystallogr., Sect. A: Found. Crystallogr., 2008, 64, 112-122.

17 V. A. Blatov, A. P. Shevchenko and V. N. Serezhkin, J. Appl. Crystallogr., 2000, 33, 1193.

18 (a) B. Gole, A. K. Bar and P. S. Mukherjee, Chem. Commun., 2011, 47, 12137-12139; (b) J. S. Qin, S. J. Bao, P. Li, W. Xie, D. Y. Du, L. Zhao, Y. Q. Lan and Z. M. Su, Chem.-Asian J., 2014, 9, 749-753. 